\title{
Protocolo de intervención contra la violencia infantil
}

\author{
Intervention protocol against child violence
}

Protocolo de intervenção contra violência infantil

Marco Antonio Mendivil Majluf damarmenmaj@hotmail.com https://orcid.org/0000-0002-0286-3622 Universidad Nacional “Siglo XX", La Paz, Bolivia

\section{RESUMEN}

\section{ABSTRACT}

\section{RESUMO}

La investigación tuvo por objetivo principal proponer la estructura con los contenidos que debe tener el "protocolo de intervención contra la violencia infantil". Usando la metodología de tipo descriptiva-propositiva. Con un enfoque cualitativo. Yun diseño documental. Los métodos utilizados fueron inductivos, análisis-síntesis, histórico-lógico, y sociológico. Se obtuvo como resultado que la ruta de atención a niñas y niños en situación de violencia, sirvió de base para la restructuración del protocolo. Por lo que se concluyó que, a través de la elaboración e implementación del "protocolo de intervención contra la violencia infantil", se podrá trazar la ruta a seguir, en el marco de la coordinación interinstitucional necesaria.

Palabras clave: Violencia; violencia infantil; ley 548; UNICEF; derechos humanos

The main objective of the research was to propose the structure with the contents that the "intervention protocol against child violence" should have. Using the descriptive - propositional methodology. With a qualitative approach. And a documentary design. The methods used were inductive, analysis-synthesis, historical-logical, and sociological. As a result, it was obtained that the route of attention to girls and boys in situations of violence served as the basis for the restructuring of the protocol. Therefore, it was concluded that, through the elaboration and implementation of the "intervention protocol against child violence", the route to be followed can be traced, within the framework of the necessary inter-institutional coordination.

Key words: Violence; child violence; law 548; UNICEF; human rights

O principal objetivo da pesquisa foi preparar um projeto de lei de reforma da Lei Orgânica Eleitoral, Código da Democracia, relativo à eleição de presidente, vice-presidente e membros dos governos autônomos de freguesia rurais descentralizados. A metodologia utilizada foi de caráter descritivo, sob abordagem mista, e de desenho documental de campo. Além disso, os métodos usados foram; analítico-sistemático; histórico-lógico e indutivo-dedutivo. Por sua vez, eles foram usados como técnicas e instrumentos; levantamento, entrevista e observação. A população do estudo foi constituída por 397 advogados cadastrados no Fórum de Advogados da Província de Morona Santiago e a amostra foi de 80 advogados. Desta forma, obteve-se a necessidade de elaboração do anteprojeto para garantir uma boa gestão administrativa. Desta forma, será adicionado um projeto de lei à legislação equatoriana que permitirá o avanço do sistema eleitoral nas freguesias rurais do país.

Palavras-chave: Violência; violência infantil; lei 548; UNICEF; direitos humanos 
Partiendo de la revisión de bases legales como la Constitución Política del Estado, los Tratados Internacionales en materia de derechos humanos ratificados por el Estado boliviano, y la normativa vigente (Código niña, niño y adolescente - Ley 548), referidas a los derechos fundamentales de niñas y niños, en relación con su interés superior, y los mecanismos para actuar en los ámbitos de la prevención, protección, acción penal y reparación ante hechos de violencia; se llega a dos primicias. La primera, respecto a la complejidad procedimental y normativa para el abordaje de la violencia contra niñas y niños, en el marco de su interés superior; y la segunda, que pone en evidencia la insuficiencia en términos generales respecto a la intervención de la normativa vigente.

Esta situación y, por ende, el contexto normativo, llevan a la determinación fundamental, en el marco de las políticas públicas a ser implementadas en temas de lucha contra la violencia hacia niñas y niños, que se genere una directriz a través de un protocolo que es elaborado e implementado por el Ministerio de Justicia y Transparencia Institucional, pero todos los elementos e insumos deben ser generados y por ende validados por todas las instancias involucradas en el presente caso, al respecto se tiene el Órgano Ejecutivo, el Órgano Judicial, el Ministerio Público, la Policía Boliviana y las Entidades Territoriales Autónomas ETAs (Gobiernos Autónomos Departamentales y Gobiernos Autónomos Municipales).

De esta forma, el Código niña, niño y adolescente - Ley 548, que tiene por objeto y finalidad reconocer, desarrollar, regular y garantizar el ejercicio de los derechos de las niñas, niños y adolescentes; no es claro en cuanto a las regulaciones dispositivas respecto a los hechos de violencia contra niñas y niños, en ese sentido se señalan los siguientes elementos para determinar los vacíos que se pretenden regular a partir del presente trabajo.

Por lo tanto, la Ley 548 que regula la materia de niñez y adolescencia ha establecido dos líneas esenciales, más no integrales (entiéndase incompletas) respecto a temas de violencia para niñas y niños, los cuales son; violencia sexual y violencia en el sistema educativo, por lo que se hace necesario establecer los alcances sobre las formas de violencia. Además de mecanismos de prevención, protección, acción penal, reparación en diferentes espacios y lugares como la familia, sociedad, instancias estatales, centros de salud, entre otros.

Asimismo, se hace referencia a la implementación de programas permanentes de prevención y atención, así como el derecho de acceso a la justicia, lo cual se constituye en el sustento normativo para la elaboración e implementación del protocolo de intervención; de esta manera, se debe tener en cuenta que el ente rector cabeza de sector en temas de niñez es el Ministerio de Justicia y Transparencia Institucional, por lo que la misma norma le faculta a esta cartera de Estado actuar como máxima instancia. 
No obstante, el otro elemento que se constituye en la base para la elaboración e implementación del protocolo de intervención es el "interés superior de la niña, niño y adolescente" principio rector para el ejercicio de los derechos fundamentales de niñas y niños; el cual se encuentra regulado en la Constitución Política del Estado, la Ley 548 y tratados internacionales en materia de derechos humanos.

En ese entendido es que necesariamente se deben hacer los abordajes conceptuales como contextuales de los tipos de violencia que se ejercen sobre niñas y niños, así como los alcances de su interés superior, ello permitirá establecer las bases para la elaboración e implementación del modelo de intervención.

En consecuencia, lo que se pretende con el "protocolo de intervención contra la violencia infantil", es que así se debe dejar claramente establecido que la población está referida a las niñas y niños conforme lo señala la Ley 548 :

Artículo 5. (sujetos de derechos). Son sujetos de derechos del presente Código, los seres humanos hasta los dieciocho (18) años cumplidos, de acuerdo a las siguientes etapas de desarrollo:

a) Niñez, desde la concepción hasta los doce (12) años cumplidos (...)

Está claramente determinado el alcance de la población, todo ello con el objeto de que los elementos sustanciales y los alcances de la investigación como del Protocolo mismo puedan ser claros y explícitos, para no generar confusión respecto a las atribuciones de las diferentes instancias.

En ese orden de cosas, se deben establecer las formas y/o tipos de violencia que se ejercen contra las niñas y niños, aspecto que de sobremanera no fue abordado y mucho menos sintetizado por el Código niña, niño y adolescente; llama la atención que se haya centrado en el sistema educativo y la violencia sexual, cuando el tema de violencia contra niñas y niños debe ser abordado de manera plenamente integral, tarea que por cuestiones metodológicas y de técnica legislativa no se puede dejar a una modificación del CNNA.

Aunado a ello, la investigación tiene por objetivo principal, proponer la estructura con los contenidos mínimos que debe tener el "Protocolo de intervención contra la violencia infantil".

Es así que, en el marco de la formulación de políticas públicas para niñas y niños por parte del Estado en todos sus niveles, corresponde que en el efectivo ejercicio de sus atribuciones las diferentes instancias del Estado (Órgano Ejecutivo, Órgano Judicial, Ministerio Público, Policía Boliviana y las Entidades Territoriales Autónomas ETAs Departamentales y Municipales), asuman sus roles de manera efectiva y coordinada, todo con el fin de erradicar la violencia contra niñas y niños. 
El Ministerio de Justicia y Transparencia Institucional como ente rector en temas de niñez y adolescencia conforme las previsiones del CNNA; debe asumir como una de las tareas primordiales el de la lucha frontal contra la violencia hacia niñas y niños, por ende, debe formular políticas públicas que planteen mecanismos de la prevención, protección, acción penal y reparación de derechos de niñas y niños ante hechos de violencia en sus diferentes magnitudes. Como elemento base se debe tomar en cuenta el interés superior de la niña, niño y adolescente, y los alcances previstos por este principio en el contexto nacional.

\section{Violencia contra niños y niñas}

Pulgar (1996) define violencia como:

Al uso de todo tipo de fuerza que de una manera consciente o inconsciente se produce contra las personas humanas, y también contra los animales irracionales y el entorno natral (lo que no es el sujeto que ejerce la violencia), que surge del egoísmo, el dominio, el odio, la venganza y otros (p.62).

De acuerdo a esta descripción, se infiere que la violencia como tal se constituye en una acción o conjunto de acciones efectuadas por una persona o una colectividad, a raíz de pensamientos negativos que se canalizan de manera agresiva, lamentablemente se dan en diferentes ámbitos que van desde el familiar, el social y el estatal en sus diferentes manifestaciones.

Mientras que Gutiérrez y Acosta (2012) conceptualiza la violencia contra niños y niñas como:

Una práctica antigua, que ha franqueado culturas, clases sociales, niveles educativos, estratos económicos y contextos históricos. En la sociedad actual, la violencia se superpone al reconocimiento de los niños y niñas como titulares de derechos, lo que se manifiesta en las estadísticas nacionales e internaciones que, si bien están muy por debajo de lo que en realidad ocurre, permiten intuir la magnitud del problema (s.n.).

Siguiendo a De Bonis (1998) la historia del maltrato a infantes sucede a partir que el ser humano se encuentra en la faz de la tierra. En tal sentido, el mismo es tan antiguo como la humanidad. En Esparta a los niños con defectos físicos se los lanzaban desde el Monte Taijeto y en la India se los estimaba como instrumentos del Diablo. Por lo tanto eran destrozados. Otro ejemplo de violencia infantil ocurrió en la Revolución Industrial, pues los niños ingresaron a laborar mas de 16 horas.

La violencia y violencia contra niñas y niños se puede inferir el hecho de que la violencia en general es de larga data, más aún la forma o las formas en que se manifiesta es totalmente variada, lo cual deviene de actitudes y expresiones totalmente negativas de las personas; por cuanto una expresión sumamente reprochable de violencia es la que se practica contra un grupo vulnerable como es la niñez y adolescencia, por lo que un objetivo central de muchos 
Estados y sociedades es el de la erradicación de la violencia en todas sus magnitudes.

De acuerdo con el Fondo de las Naciones Unidas para la Infancia se contempla lo siguiente::

La violencia contra los niños y niñas incluye el abuso y maltrato físico y mental, el abandono o el tratamiento negligente, la explotación y el abuso sexual. La violencia puede ocurrir en el hogar, las escuelas, los orfelinatos, los centros residenciales de atención, en las calles, en el lugar de trabajo, en prisiones y establecimientos penitenciarios. Puede afectar la salud física y mental de los niños, perjudicar su habilidad para aprender y socializar, y, más adelante, socavar su desarrollo como adultos funcionales y buenos progenitores. En los casos más graves, la violencia contra los niños conduce a la muerte (UNICEF, 2006).

En lo que concierne a este grupo vulnerable, se establecen como tipos y/o formas de violencia ejercida contra niñas y niños el abuso y maltrato físico y mental, el abandono o tratamiento negligente, la explotación y el abuso sexual; elementos que son planteados de manera más específica y señalan la línea que se debe seguir para las determinaciones previstas. Asimismo, y este es un punto importante a tomar en cuenta, son los lugares donde se ejerce violencia contra la niñez, o donde la misma puede ocurrir, y entre otros se tiene el hogar, la escuela, los orfelinatos, residenciales, calles, trabajo, centros penitenciarios, prisiones, entre otros.

En ese entendido Dworkin (1989) manifiesta lo siguiente:

Desde el reconocimiento explícito de un catálogo de derechos, se superan las expresiones programáticas del "interés superior del niño" y es posible afirmar que el interés superior del niño es la plena satisfacción de sus derechos. El contenido del principio son los propios derechos; interés y derechos, en este caso, se identifican. Todo "interés superior" pasa a estar mediado por referirse estrictamente a lo "declarado derecho"; por su parte, sólo lo que es considerado derecho puede ser "interés superior (s.n.).

Esta definición plantea un alcance muy importante y determinante respecto al principio que se analiza, es decir que se habla de la plena satisfacción, entendida como el ejercicio pleno de los derechos fundamentales de niños y niñas, es decir el ejercicio de derechos por sí mismos, no a través de terceros, que podrían ser padres, tutores, autoridades de diferente índole, entre otras, en consecuencia todo lo que tenga que ver con los derechos de los menores se encuentra sintetizado y a la vez señalado en su amplia expresión: derechos humanos de niñas y niños.

Asimismo, la Opinión Consultiva OC-17/2002 de 28 de agosto señaló lo siguiente:

Este principio regulador de la normativa de los derechos del niño se funda en la dignidad misma del ser humano, en las características propias de los niños, y en la necesidad de propiciar el desarrollo de éstos, con pleno aprovechamiento de sus potencialidades, así como en la naturaleza y alcances de la Convención sobre los Derechos del Niño. 
De manera concreta, el Sistema Interamericano a través de esta Opinión Consultiva que fue requerida por la Comisión Interamericana de Derechos Humanos en el marco de la condición jurídica y los derechos humanos del niño, deja claramente establecido el hecho de la condición de ser humano que tienen los menores de edad a la luz de los derechos humanos señalados y delineados de manera concreta en el marco de las previsiones de la Convención sobre los Derechos del Niño, en tal sentido como ya se había concluido, el ejercicio de los derechos fundamentales por parte de los niños se hace de manera directa por los mismos, lo cual se los considera como sujetos de derechos de manera plena.

\section{Tratados internacionales en materia de Derechos Humanos}

En este acápite se analizan los principales tratados internacionales en materia de derechos humanos relacionados a niñas y niños, que fueron ratificados por el Estado boliviano.

\section{Sistema de Naciones Unidas. Convención sobre los derechos del niño}

En los artículos 2, 3, 4 y 19 de la Convención sobre los derechos del niño, hace referencia de cómo el tratado internacional por excelencia es considerado para el análisis y abordaje de los derechos humanos de niñas y niños, por lo que se debe hacer énfasis en el hecho de que son imperantes los principios de no distinción y/o discriminación por ninguna naturaleza y del interés superior de la niña, niño y adolescente, por lo cual, los menores de edad son considerados como sujetos de derechos para el pleno goce y ejercicio de los mismos, por cuanto los Estados en todos sus niveles deberán adoptar las medidas legislativas, políticas públicas, asignación de recursos económicos, etc., para la efectivización de estos postulados.

Es así que una de las tareas primordiales para el Estado como para la sociedad, es el de la lucha frontal contra toda forma de violencia contra niñas y niños, en cualquier tipo de contexto o espacio.

\section{Sistema Interamericano de Derechos Humanos}

\section{Convención Americana sobre derechos humanos (Pacto de San José de Costa Rica)}

En su artículo 16 sobre los derechos de la niñez, hace referencia a la protección de niñas y niños, constituyéndose uno de los elementos del principio del interés superior de la niña, niño y adolescente, lo cual implica que el ejercicio de sus derechos humanos contempla que sea protegido por la sociedad y el Estado en todas sus dimensiones frente a todo tipo de violencia.

En ese sentido, los mecanismos de protección estarán contemplados en instrumentos normativos, emanados de los órganos legislativos de los Estados en todos sus niveles, teniendo como 
soporte esencial los tratados internacionales como el texto constitucional; pero la emisión de normas no será suficiente, por ende, se deben prever cuestiones prácticas y financieras para la aplicación e implementación de aquellas normas.

\section{Constitución Política del Estado y Legislación Nacional Vigente}

De acuerdo al texto constitucional, en su artículo 15, 58, 59, 60 y 61 , se infiere que el derecho a no sufrir violencia física, sexual o psicológica se encuentra categorizado como un derecho fundamental para las mujeres, pero también para niñas y niños considerados todos ellos como grupos vulnerables, teniendo en cuenta el contexto social y cultural de Bolivia.

Asimismo, cabe hacer énfasis en el hecho de que se deben establecer los mecanismos para garantizar el derecho integral de niñas y niños, por ende, se deberá sancionar toda forma de violencia contra los mismos, pues este extremo afecta su interés superior pues coarta el ejercicio pleno de sus derechos fundamentales.

\section{Código niña, niño y adolescente Ley 548, de 17 de julio de 2014}

Para la investigación se tomaron en cuenta los artículos 145, 146,147, 148, 150, 151, 155, 157 de la Ley 548. En este punto se consideraron las disposiciones normativas emanadas del Código niña, niño y adolescente Ley 548 , en lo concerniente a la violencia y los derechos fundamentales que de este aspecto se desprenden, no obstante de ello corresponde señalar que la Ley 548 aborda de manera general los tipos de violencia contra niñas y niños, asimismo hace énfasis en la violencia sexual (como forma de violencia) y en la violencia en el Sistema Educativo Plurinacional (como lugar donde se dan hechos de violencia contra niñas y niños), o sea sí se mencionan otras formas de violencia, más no se tiene referencia de otros lugares en los que las niñas y niños son vulnerables a ser víctimas de violencia. Sin embargo, y en el marco del objetivo general y los objetivos específicos del presente trabajo, no se plantean modificaciones en la Ley 548, lo cual implicaría voluntad política en el órgano legislativo además de una correlación de fuerzas así como una corriente efectivamente favorable a este grupo vulnerable; por ello que la tarea señalada es de dimensiones más objetivas y a la vez puntuales, lo cual contempla la elaboración e implementación de un "Protocolo de intervención contra la violencia infantil", que plantee alcances más efectivos y que realmente consideren elementos de la mencionada Ley 548 , otras normativas, el texto constitucional así como los tratados internacionales en materia de derechos humanos.

Si bien la Convención sobre los Derechos del Niño establece que niño es todo ser humano menor de 18 años, la Ley 548 establece una diferenciación etaria entre niños y adolescentes, al respecto es necesario dejar claramente establecido que los alcances de la investigación son para niñas y niños conforme la caracterización señalada en el Código niña, niño y adolescente, y es que por las dimensiones y elementos configurativos de este trabajo de investigación se hizo necesario poner los límites señalados por las normas de investigación. 


\section{Características de la ruta de atención a niñas y niños en situación de violencia}

\section{Ruta de atención}

Sobre la "ruta de atención" se tiene la siguiente definición:

La ruta de atención integral para víctimas de violencias de género se entiende como el conjunto de acciones articuladas que responden a los mandatos normativos para garantizar la protección de las víctimas, su recuperación y la restitución de los derechos. Comprende las actuaciones internas de cada institución para abordar a la víctima de acuerdo con sus competencias y la coordinación de las intervenciones intersectoriales (Ministerio de Salud y Protección Social, 2017).

Al respecto se puede señalar que la ruta de atención está configurada por las acciones y atribuciones institucionales, que se desprenden de la normativa vigente para intervenir ante niñas y niños víctimas de violencia. Estos elementos serán desarrollados en el presente punto.

\section{Roles Institucionales en la ruta de atención a niñas y niños en situación de violencia}

En este punto se deben tener en cuenta que existen una serie de instituciones de los diferentes órganos como niveles del Estado que coadyuvan en las medidas y mecanismos de apoyo y colaboración a niñas y niños en situación de violencia, no obstante, de ello es pertinente señalar que algunos de esos espacios que sirven para brindar ese apoyo, también se constituyen en instancias donde se generan hechos de violencia.

Es así que las instancias estatales que coadyuvan en las medidas y mecanismos de apoyo y colaboración a niñas y niños en situación de violencia son los siguientes:

- Ministerio de Justicia y Transparencia Institucional

- Sistema de Salud

- Sistema Educativo

- Servicio Legal Integral Municipal

- Defensoría de la Niñez y Adolescencia

- Ministerio Público

- Policía Boliviana

- Órgano Judicial

- Casas de acogida y refugio temporal y,

- guarderías, centros infantiles integrales y centros de acogimiento. 
La investigación se desarrolló bajo una metodología de tipo descriptiva - propositiva. Con un enfoque cualitativo. Y un diseño documental, ya que, se recogió conceptos de fuentes bibliográficas para la elaboración de un marco teórico sobre los elementos conceptuales violencia en general, violencia contra niñas y niños, e interés superior del menor.

Los métodos utilizados fueron inductivos, análisis-síntesis, histórico-lógico, y sociológico.

Inductivo. Este método analizó una porción de un todo, parte de lo particular a lo general, de lo individual a lo universal, consistió en sacar de los hechos particulares una conclusión general, es así que en el caso concreto se abordaron determinados elementos y definiciones de aspectos que con el transcurso del trabajo de investigación se llegó a cuestiones muy generales.

Análisis -síntesis. Consistió en la separación de las partes de un todo para estudiarlas en forma individual y la reunión racional de elementos dispersos para estudiarlos en su totalidad, lo cual pudo apreciarse con exactitud en el marco teórico conceptual respecto al análisis y valoración de elementos de forma particular.

Histórico- lógico. Se utilizó este método para contextualizar el objeto de estudio, puesto que permitió el orden cronológico de la secuencia de hechos que lo configuran.

Sociológico. Con este método se verificó la correspondencia existente entre la ciencia del derecho y las relaciones sociales económicas, de manera que se abordó los diferentes fenómenos sociales que conforman los elementos conceptuales de los diferentes elementos que se analizan. La importancia de dicho método radicó también en la "dialéctica", que como ciencia explica un conjunto de principios científicos sistematizadores del movimiento de la sociedad en general, comprendida como una unidad material del mundo.

\section{RESULTADOS}

Abordado en términos conceptuales y contextuales todos los elementos que conforman la violencia contra niñas y niños, el interés superior de la niña, niño y adolescente; así como las etapas y roles institucionales en la ruta de atención a niñas y niños en situación de violencia; lo que corresponde es establecer la ruta en términos de la configuración completa que se tiene sobre este punto, lo cual permitió tener el elemento sustancial y, por ende, base que sirvió para el "protocolo de Intervención contra la violencia infantil". 


\begin{tabular}{|c|c|c|c|c|c|c|}
\hline & \multicolumn{6}{|c|}{ LUGARES DONDE SE EJERCE VIOLENCIA CONTRA NIÑAS Y NIÑOS } \\
\hline & HOGAR Y FAMILIA & SISTEMA PENITENCIARIO & ESPACIOS DE TRABAJO & COMUNIDAD & SISTEMA DE SALUD & SISTEMA EDUCATIVO \\
\hline 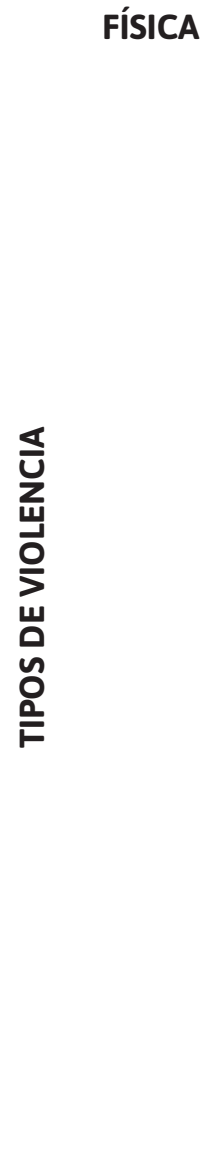 & $\begin{array}{l}\text { Violencia física es el uso } \\
\text { deliberado de fuerza } \\
\text { física contra uniño o una } \\
\text { niña que resulta en o } \\
\text { tiene gran probabilidad } \\
\text { de resultar en daño para } \\
\text { la salud, supervivencia, } \\
\text { desarrollo o dignidad } \\
\text { del niño o niña. Hay } \\
\text { niños y niñas de todo } \\
\text { el mundo que sufren } \\
\text { golpes, patadas, } \\
\text { zarandeo, azotamiento, } \\
\text { mordiscos, quemaduras, } \\
\text { e st } r \text { a n u l a c i ón, } \\
\text { envenenamiento y } \\
\text { asficia a manos de } \\
\text { mienbros de su familia. } \\
\text { En casos extemos, } \\
\text { esta violencia puede } \\
\text { provocar la muerte, } \\
\text { discapacidad o lesiones } \\
\text { físicas graves. En otros } \\
\text { casos, la violencia física } \\
\text { puede no dear ninguna } \\
\text { señal externa visible. }\end{array}$ & $\begin{array}{l}\text { Un grupo especialmente } \\
\text { en riesgo de sufrir violencia } \\
\text { en las prisiones y otros } \\
\text { centro de privación de } \\
\text { libertard, lo forman los } \\
\text { bebés y niños pequeños } \\
\text { que están en prisión con } \\
\text { sus madres. Esta práctica } \\
\text { existe en muchos países, } \\
\text { en todas las regiones. Sin } \\
\text { embargo, las instituciones } \\
\text { rara vez brindan las } \\
\text { condiciones necesarias } \\
\text { para protegerles. Existen } \\
\text { beneficios innegables de } \\
\text { mantenera los niñosyniñas } \\
\text { con sus madres; algunos } \\
\text { paísses sólo permiten a } \\
\text { los bebés permanecer con } \\
\text { sus madres, otros permiten } \\
\text { a las madres quedarse } \\
\text { con sus hijos hasta los } \\
\text { seis años. Sin embargo, se } \\
\text { requiere urgentemente } \\
\text { mejorar las condiciones } \\
\text { bajo las que funcionan } \\
\text { estas instituciones para } \\
\text { satisfacer las necesidad } \\
\text { específicas de los niños } \\
\text { y niñas. Por ejemplo, } \\
\text { un estudio de Camboya } \\
\text { halló que algunos niños y } \\
\text { niñas eran golpeados por } \\
\text { otros prisioneros cuando } \\
\text { lloraban o como resultado } \\
\text { de una disputa con su } \\
\text { madre. }\end{array}$ & $\begin{array}{l}\text { De todos los entornos en los } \\
\text { que los niños y niñas están } \\
\text { expuestos a la violencia, } \\
\text { el lugar de trabajo es el } \\
\text { más difícil de abordar. } \\
\text { Según los instrumentos } \\
\text { internacionales y la mayoría } \\
\text { de las leyes nacionales, los } \\
\text { niños y niñas menores de } \\
\text { cierta edad /usualmente } \\
\text { quince años, pero a veces } \\
\text { menos) no deben estar en } \\
\text { el entorno laboral y menos } \\
\text { aún en un lugar de trabajo } \\
\text { donde puedan estar sujetos } \\
\text { a violencia. Pero más de } \\
\text { doscientos millones de } \\
\text { niños y niñas en todo el } \\
\text { mundo si trabajan, con } \\
\text { edades tanto por debajo } \\
\text { como por encima de la } \\
\text { edad mínima legal, muchos } \\
\text { sufren maltrato, violencia } \\
\text { física, psicológica y abuso } \\
\text { verbal y sexual. } \\
\text { La violencia es un aspecto } \\
\text { olvidado en los debates } \\
\text { relativos al trabajo } \\
\text { infantil; hay pocos datos } \\
\text { disponibles, especialmente } \\
\text { sobre los niños y niñas que } \\
\text { trabajan en la economía } \\
\text { informal, que son la } \\
\text { mayoría. }\end{array}$ & $\begin{array}{l}\text { Ninguna comunidad está } \\
\text { libre de violencia. Sin } \\
\text { embargo, el riesgo de } \\
\text { encontrarse con violencia, } \\
\text { tanto contra como por } \\
\text { parte de niños y niñas, es } \\
\text { mucho más alto en unas } \\
\text { comunidades que en otras. } \\
\text { En algunos entornos, } \\
\text { especialmente aquellos } \\
\text { en los que hay muchas } \\
\text { armas en circulación, la } \\
\text { violencia ha alcanzado } \\
\text { proporciones alarmantes } \\
\text {-se trata normalmente } \\
\text { de áreas urbanas en } \\
\text { regiones con altos niveles } \\
\text { de pobreza, disparidad } \\
\text { económica y desigualdad } \\
\text { social y afectadas por } \\
\text { una inestabilidad política } \\
\text { o económica continua. Al } \\
\text { mismo tiempo, también } \\
\text { han sido documentados } \\
\text { niveles alarmantes de } \\
\text { violencia contra los niños } \\
\text { y niñas en sociedades } \\
\text { relativamente ricas y } \\
\text { estables, especialmente } \\
\text { donde hay desigualdades } \\
\text { profundas. }\end{array}$ & $\begin{array}{l}\text { Todas las formas de } \\
\text { violencia interpersonal } \\
\text { acarrean resultados } \\
\text { sanitarios negativos y el } \\
\text { sistema de salud debería } \\
\text { afrontarlas. Ahora bien, } \\
\text { hay poderosas razones } \\
\text { para poner la mira en la } \\
\text { violencia contra niñas y } \\
\text { niños que soportan una } \\
\text { enorma carga de tipos } \\
\text { específicos de violencia } \\
\text { que están enraizados } \\
\text { en una desigualdad y } \\
\text { discriminación entre } \\
\text { los sexos socialmente } \\
\text { acepatadas y por ende } \\
\text { están sancionados, pese a } \\
\text { constituir una violencia de } \\
\text { susderechos humanos. Por } \\
\text { ello, niñas y niños sufren } \\
\text { verguenza y oprobios } \\
\text { y la violencia suele } \\
\text { quedar escondida. Con } \\
\text { demasiada frecuencia, las } \\
\text { institutciones sanitarias } \\
\text { y de otra índole tardan } \\
\text { en reconocer y enfrentar } \\
\text { esta violencioa y no hay } \\
\text { servicios disponibles o } \\
\text { bien su capacidad es } \\
\text { limitada. }\end{array}$ & $\begin{array}{l}\text { Las formas de violencia } \\
\text { que se producen en la } \\
\text { escuela son tanto físicas } \\
\text { como psicológicas y } \\
\text { generalmente se dan al } \\
\text { mismo tiempo. Las formas } \\
\text { de violencias utilizadas } \\
\text { por los educadores y otros } \\
\text { funcionarios de la escuela } \\
\text { (con o sin la aprobación } \\
\text { tácita o explícita de los } \\
\text { ministerios de educación } \\
\text { y de otras autoridades } \\
\text { que vigilan las escuelas) } \\
\text { incluyen: el castigo físico } \\
\text { y otras formas crueles y } \\
\text { degradantes de castigo } \\
\text { o trato. La violencia } \\
\text { sexual y violencia basada } \\
\text { en el género y el acso. } \\
\text { Las formas de violencia } \\
\text { protagonizadas por los } \\
\text { niños y niñas incluyen: la } \\
\text { intimidación, la violencia } \\
\text { sexual y violencia basada } \\
\text { en el género, las peleas } \\
\text { en el patio de la escuel, la } \\
\text { violencia pandillera y la } \\
\text { agresión con armas. }\end{array}$ \\
\hline
\end{tabular}




\section{LUGARES DONDE SE EJERCE VIOLENCIA CONTRA NIÑAS Y NIÑOS}

\begin{tabular}{|c|c|c|c|c|c|c|c|}
\hline & & HOGAR Y FAMILIA & SISTEMA PENITENCIARIO & ESPACIOS DE TRABAJO & COMUNIDAD & SISTEMA DE SALUD & SISTEMA EDUCATIVO \\
\hline 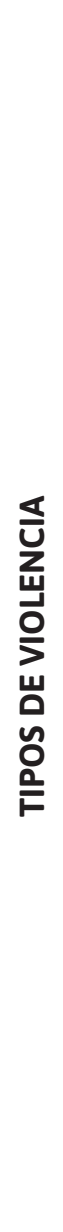 & $\begin{array}{l}\text { SEXUAL } \\
\text { NEGLIGENCIA }\end{array}$ & $\begin{array}{l}\text { Toda violencia física y } \\
\text { sexual, implica daño } \\
\text { psicológico, pero la } \\
\text { violencia psicológica } \\
\text { también puede adoptar la } \\
\text { forma de insultos, injurias, } \\
\text { aislamiento, rechazo, } \\
\text { amenazas, indiferencia } \\
\text { emocional y menosprecio, } \\
\text { todas perfudiciales para } \\
\text { el desarrollo psicológico } \\
\text { y bienestar de los niños y } \\
\text { niñas. } \\
\text { Mucha de esta violencia } \\
\text { sexual es protagonizada } \\
\text { por miembros de la familia } \\
\text { u otras personas que } \\
\text { residen o visitan el hogar } \\
\text { familiar, personas en las } \\
\text { que normalmente confían } \\
\text { los niños y niñas y que a } \\
\text { menudo son responsables } \\
\text { de su cuidado. } \\
\text { El trato negiblente es un } \\
\text { importante factor que } \\
\text { contribuye a la muerte y } \\
\text { a la enfermedad de los } \\
\text { niños y niñas pequeños. } \\
\text { Trato negligente (o } \\
\text { descuido) significa que los } \\
\text { progenitores o encargados } \\
\text { del cuidado no cumplen } \\
\text { las necesidades físicas y } \\
\text { emocionales de un niño } \\
\text { o niña cuando tienen los } \\
\text { medios, el conocimiento } \\
\text { y el acceso a servicios } \\
\text { para hacerlo o que no lo } \\
\text { protegen de la exposición } \\
\text { al peligro. }\end{array}$ & & $\begin{array}{l}\text { De todos los entornos en los } \\
\text { que los niños y niñas están } \\
\text { expuestos a la violencia, } \\
\text { el lugar de trabajo es el } \\
\text { más difícil de abordar. } \\
\text { Según los instrumentos } \\
\text { internacionales y la mayoría } \\
\text { de las leyes nacionales, los } \\
\text { niños y niñas menores de } \\
\text { cierta edad /usualmente } \\
\text { quince años, pero a veces } \\
\text { menos) no deben estar en } \\
\text { el entorno laboral y menos } \\
\text { aún en un lugar de trabajo } \\
\text { donde puedan estar sujetos } \\
\text { a violencia. Pero más de } \\
\text { doscientos millones de } \\
\text { niños y niñas en todo el } \\
\text { mundo si trabajan, con } \\
\text { edades tanto por debajo } \\
\text { como por encima de la } \\
\text { edad mínima legal, muchos } \\
\text { sufren maltrato, violencia } \\
\text { física, psicológica y abuso } \\
\text { verbal y sexual. }\end{array}$ & $\begin{array}{l}\text { A los efecto de este acápite, } \\
\text { la comunidad incluye } \\
\text { cualquier espacio usado } \\
\text { u ocupado por los niños y } \\
\text { niñas fuera del hogar, la } \\
\text { escuela, las instituciones } \\
\text { y los lugares de trabajos } \\
\text { organizados, que son } \\
\text { tema de otros acápites. Sin } \\
\text { embargo, hay que recordar } \\
\text { que la comunidad no es } \\
\text { solamente un espacio físico } \\
\text { sino también un ambiente } \\
\text { social. Los niños y niñas } \\
\text { nacen y se crían en un } \\
\text { marco de comportameintos, } \\
\text { actitudes, costumbres y } \\
\text { creencias y son socializados } \\
\text { en élpara para interactuar } \\
\text { con el mundo y aprender a } \\
\text { manejar la red de relaciones } \\
\text { e instituciones que forman } \\
\text { el contexto no familiar de } \\
\text { sus vidas. }\end{array}$ & & $\begin{array}{l}\text { La tecnología proporciona } \\
\text { un nuevo medio para } \\
\text { el acoso o intimidación } \\
\text { mediante el uso de } \\
\text { Internet y el teléfono } \\
\text { celular y ha dado origen } \\
\text { a nuevos términos como } \\
\text { "ciber-matón" (cyber- } \\
\text { bully) y "ciber-acoso" } \\
\text { (cyber-bullying) }\end{array}$ \\
\hline
\end{tabular}


INSTANCIAS ESTATALES DE APOYO INTEGRAL A NIÑAS Y NIÑOS

\begin{tabular}{|c|c|c|c|c|c|c|c|c|c|c|c|}
\hline & & $\begin{array}{l}\text { MINISTERIO } \\
\text { DE JUSTICIA Y } \\
\text { TRANSPARENCIA } \\
\text { INSTITUCIONAL }\end{array}$ & $\begin{array}{c}\text { SISTEMA } \\
\text { DE SALUD }\end{array}$ & $\begin{array}{l}\text { INSTANCIAS } \\
\text { SISTEMA } \\
\text { EDUCATIVO }\end{array}$ & $\begin{array}{l}\text { SERVICIO LEGAL } \\
\text { INTEGRAL } \\
\text { MUNICIPAL }\end{array}$ & $\begin{array}{l}\text { DEFENSORÍA } \\
\text { DE LA NIÑEZ Y } \\
\text { ADOLESCENCIA }\end{array}$ & $\begin{array}{l}\text { MINISTERIO } \\
\text { PÚBLICO }\end{array}$ & $\begin{array}{l}\text { POLICIA } \\
\text { BOLIVIANA }\end{array}$ & $\begin{array}{l}\text { ÓRGANO } \\
\text { JUDICIAL }\end{array}$ & $\begin{array}{c}\text { CASAS DE } \\
\text { ACOGIDA } \\
\text { Y REFUGIO } \\
\text { TEMPORAL }\end{array}$ & $\begin{array}{l}\text { GUARDERIAS, } \\
\text { CENTROS } \\
\text { INFANTILES } \\
\text { INTEGRALES Y } \\
\text { CENTROS DE } \\
\text { ACOGIMIENTO }\end{array}$ \\
\hline 熟 & $\begin{array}{l}\text { PREVENCIÓN } \\
\text { ATENCIÓN Y } \\
\text { PROTECCIÓN } \\
\text { ACCIÓN PENAL }\end{array}$ & $\begin{array}{l}\text { Código Niña, } \\
\text { Niño y } \\
\text { Adolescente } \\
\text { Ley } 548 \\
\\
\text { Artículo } 179 . \\
\text { (Ministerio de } \\
\text { Justicia y } \\
\text { Transparencia } \\
\text { Institucional). } \\
\text { Son } \\
\text { atribuciones } \\
\text { del Ministerio } \\
\text { de Justicia y } \\
\text { Transparencia } \\
\text { Institucional, como } \\
\text { ente rector del } \\
\text { Sistema Plurinacional } \\
\text { de Protección } \\
\text { Integral de la Niña, } \\
\text { Niño y Adolescente: } \\
\text { a) Elaborar la } \\
\text { propuesta base } \\
\text { de politicas para } \\
\text { las niñas, niños y } \\
\text { adolescentes, y el } \\
\text { Plan Plurinacional } \\
\text { para la iñá, Niño y } \\
\text { Adolescente; (...) }\end{array}$ & $\begin{array}{l}\text { Resolución } \\
\text { WHA49.25 } \\
\text { Prevención } \\
\text { de la violencia: } \\
\text { una prioridad } \\
\text { de salud } \\
\text { pública de } \\
\text { 25 de mayo } \\
\text { de 1996, } \\
\text { emitida } \\
\text { porl la } \\
\text { Asamblea } \\
\text { Mundial de } \\
\text { la Salud que } \\
\text { dispuso: } \\
\text { 1. Declara que } \\
\text { la violencia } \\
\text { es un importante } \\
\text { problema de salud } \\
\text { pública en todo el } \\
\text { mundo; (..) } \\
\text { 3. Pide al director } \\
\text { general que, en la } \\
\text { medidden que lo } \\
\text { permitan los recursos } \\
\text { disponibles, emprenda } \\
\text { actividades de salud } \\
\text { pública para abordar } \\
\text { el problema de la } \\
\text { violencia, con objeto } \\
\text { de: } \\
\text { 1) Caracterizar los } \\
\text { diferentes tipos de } \\
\text { violencia, definin su } \\
\text { magnitud y evaluar las } \\
\text { causas de la violencia } \\
\text { y sus } \\
\text { repercusiones } \\
\text { de salud pública, } \\
\text { incorporando }\end{array}$ & 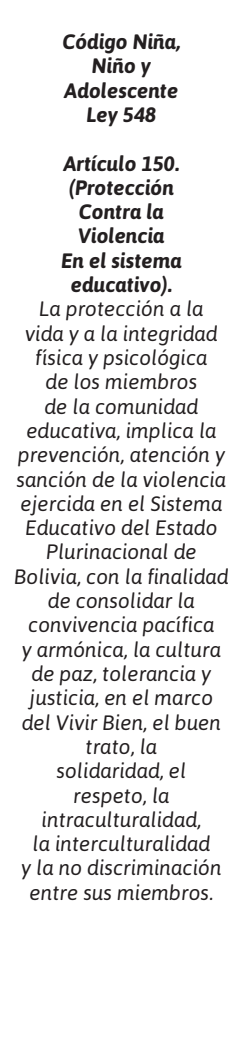 & 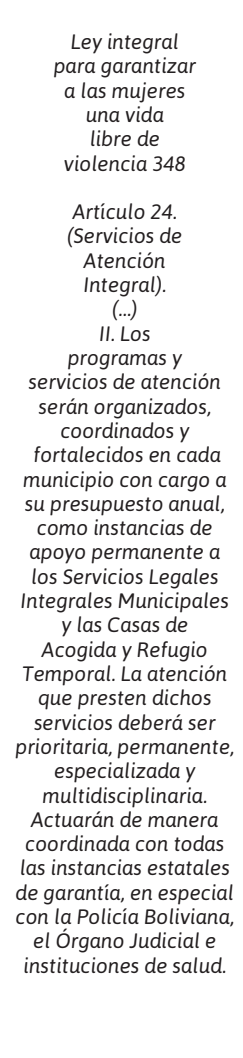 & 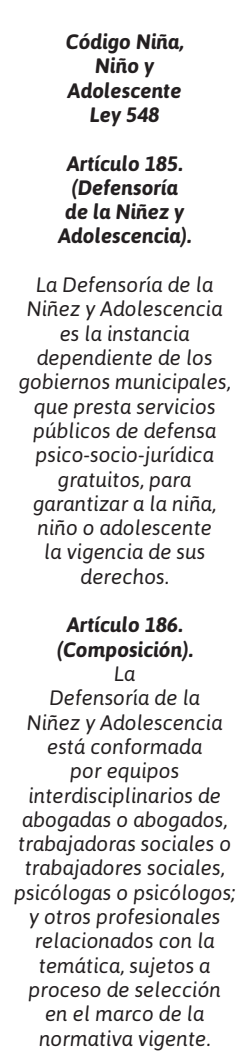 & 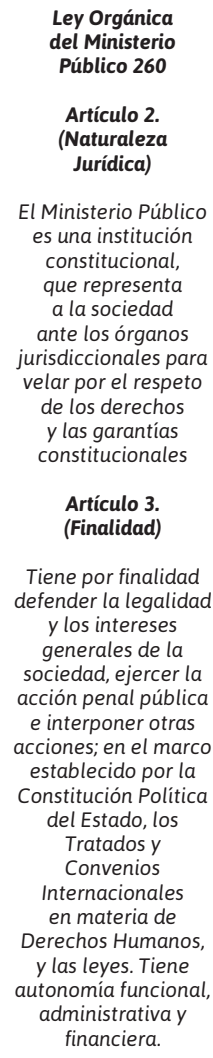 & 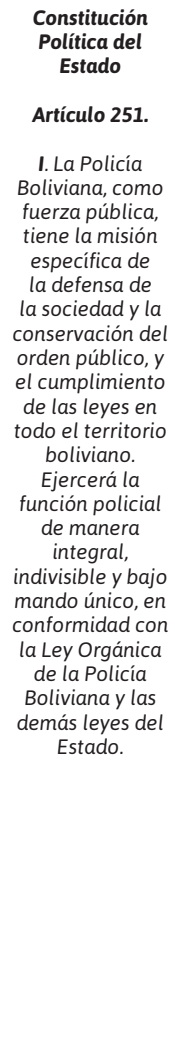 & 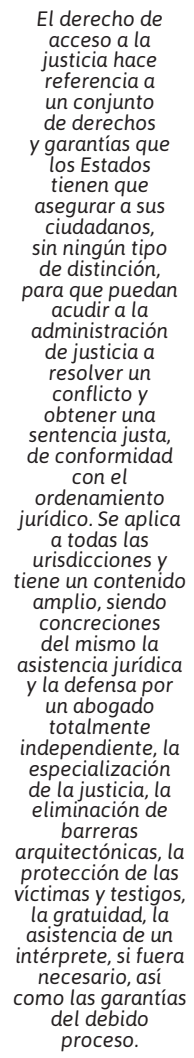 & $\begin{array}{c}\text { Ley integral } \\
\text { para garantizar } \\
\text { a las mujeres } \\
\text { una vida libre de } \\
\text { violencia } 348 \\
\text { Artículo } 25 . \\
\text { (Casas de } \\
\text { acogiday } \\
\text { refugio } \\
\text { temporal). } \\
\text { Las Entidades } \\
\text { Territoriales } \\
\text { Autónomas, en } \\
\text { el marco de sus } \\
\text { competencias y } \\
\text { sostenibilidad } \\
\text { financiera, } \\
\text { teienen la } \\
\text { responsabilidad } \\
\text { de crear, equipar, } \\
\text { mantener } \\
\text { atender Casas } \\
\text { de Acogida } \\
\text { y Refugio } \\
\text { Temporal para } \\
\text { mujeres en } \\
\text { situación de } \\
\text { violencia en el } \\
\text { area urbana } \\
\text { rural. }\end{array}$ & 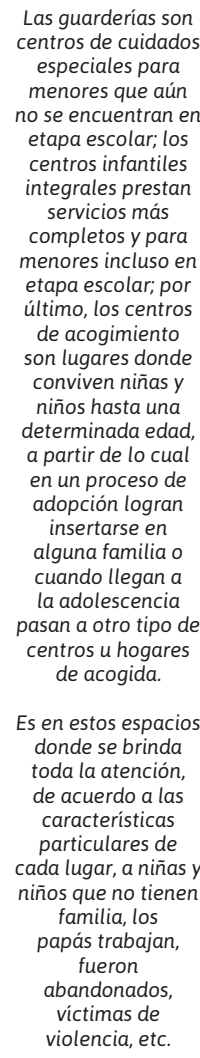 \\
\hline
\end{tabular}


INSTANCIAS ESTATALES DE APOYO INTEGRAL A NIÑAS Y NIÑOS

\begin{tabular}{|c|c|c|c|c|c|c|c|c|c|c|c|}
\hline & & $\begin{array}{l}\text { MINISTERIO } \\
\text { DE JUSTICIA Y } \\
\text { TRANSPARENCIA } \\
\text { INSTITUCIONAL }\end{array}$ & $\begin{array}{c}\text { SISTEMA } \\
\text { DE SALUD }\end{array}$ & $\begin{array}{l}\text { INSTANCIAS } \\
\text { SISTEMA } \\
\text { EDUCATIVO }\end{array}$ & $\begin{array}{l}\text { SERVICIO LEGAL } \\
\text { INTEGRAL } \\
\text { MUNICIPAL }\end{array}$ & $\begin{array}{l}\text { DEFENSORÍA } \\
\text { DE LA NIÑEZ Y } \\
\text { ADOLESCENCIA }\end{array}$ & $\begin{array}{l}\text { MINISTERIO } \\
\text { PÚBLICO }\end{array}$ & $\begin{array}{l}\text { POLICIA } \\
\text { BOLIVIANA }\end{array}$ & $\begin{array}{l}\text { ÓRGANO } \\
\text { JUDICIAL }\end{array}$ & $\begin{array}{c}\text { CASAS DE } \\
\text { ACOGIDA } \\
\text { Y REFUGIO } \\
\text { TEMPORAL }\end{array}$ & $\begin{array}{c}\text { GUARDERIAS, } \\
\text { CENTROS } \\
\text { INFANTILES } \\
\text { INTEGRALES Y } \\
\text { CENTROS DE } \\
\text { ACOGIMIENTO }\end{array}$ \\
\hline$\frac{n}{\frac{a}{\alpha}}$ & $\begin{array}{l}\text { PREVENCIÓN } \\
\text { ATENCIÓN Y } \\
\text { PROTECCIÓN } \\
\text { ACCIÓN PENAL }\end{array}$ & 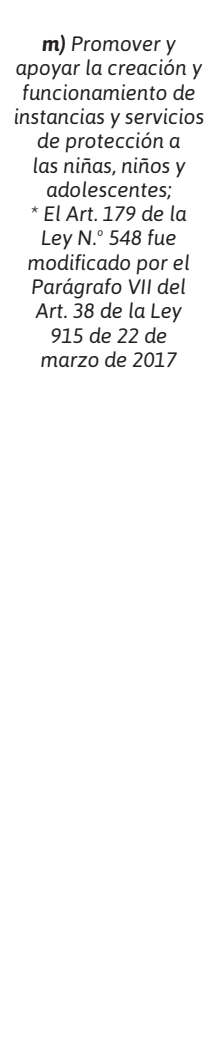 & $\begin{array}{l}\text { asimismo en el análisis } \\
\text { una perspectiva } \\
\text { basada en las } \\
\text { diferencias entre los } \\
\text { sexos; } \\
\text { 2) Evaluar los tipos } \\
\text { y la eficacia de las } \\
\text { medidas y programas } \\
\text { destinados a prevenir } \\
\text { la violencia y mitigar } \\
\text { sus efectos, prestando } \\
\text { especial atención } \\
\text { a las iniciativas } \\
\text { de orientación } \\
\text { comunitaria; } \\
\text { 3) Promover } \\
\text { actividades para } \\
\text { resolver este } \\
\text { problema a nivel tanto } \\
\text { internacional como de } \\
\text { pais, inclusive medidas } \\
\text { tendentes a: } \\
\text { a) mejorar el } \\
\text { reconocimiento, } \\
\text { la notificación y } \\
\text { la gestión de las } \\
\text { consecuencias de la } \\
\text { violencia; } \\
\text { b) promover una } \\
\text { mayor participación } \\
\text { intersectorial en la } \\
\text { prevención y la gestión } \\
\text { de la violencia; }\end{array}$ & & 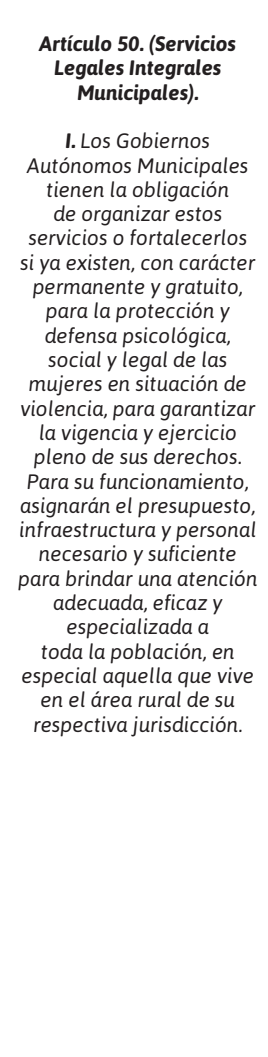 & 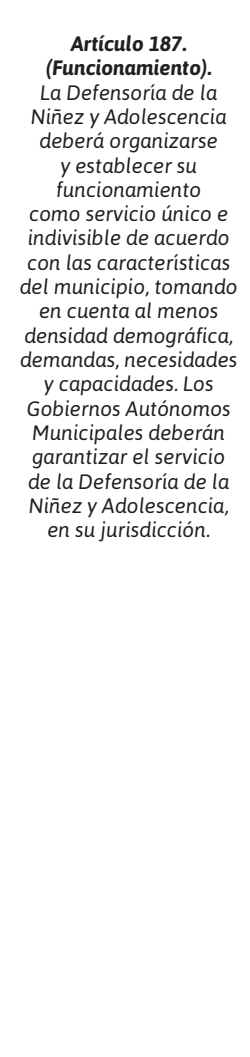 & & $\begin{array}{l}\text { Constitución } \\
\text { Polititica del Estado } \\
\text { Artículo } 251 . \\
\text { 1. La Policía } \\
\text { Boliviana, como } \\
\text { fuerza pública, } \\
\text { tiene la misión } \\
\text { especifica de } \\
\text { la defensa de } \\
\text { la sociedady y la } \\
\text { conservación del } \\
\text { orden público, y } \\
\text { el cumplimiento } \\
\text { de las leyes en } \\
\text { todo el territorio } \\
\text { boliviano. } \\
\text { Ejercerá la } \\
\text { función policial de } \\
\text { manera integral, } \\
\text { indivisible y bajo } \\
\text { mando único, en } \\
\text { conformidad con } \\
\text { la Ley Orgánica } \\
\text { de la policía } \\
\text { Boliviana y las } \\
\text { demás leyes del } \\
\text { Estado. }\end{array}$ & $\begin{array}{l}\text { *Conde, M.J. } \\
\text { Elacceso a la } \\
\text { justicia de niños, } \\
\text { ninas y joveneses. } \\
\text { Disponible en: } \\
\text { https:// www. } \\
\text { corteidh.or.cr/ } \\
\text { tabloas. } \\
\text { /r25534.pdf }\end{array}$ & 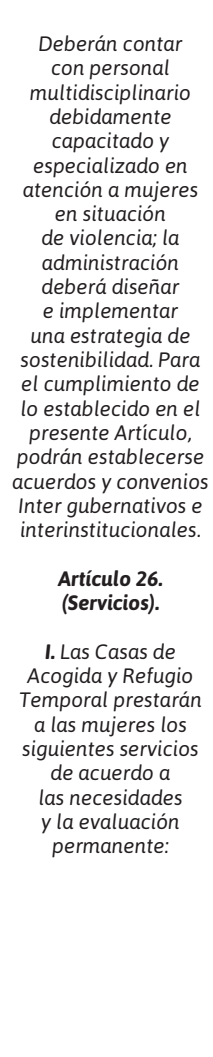 & 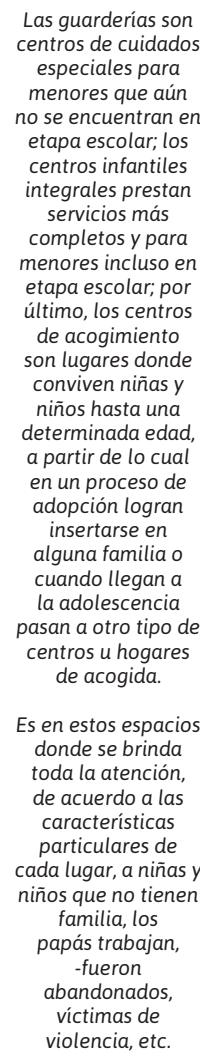 \\
\hline
\end{tabular}


INSTANCIAS ESTATALES DE APOYO INTEGRAL A NIÑAS Y NIÑOS

\begin{tabular}{|c|c|c|c|c|c|c|c|c|c|c|c|}
\hline & & $\begin{array}{l}\text { MINISTERIO } \\
\text { DE JUSTICIA Y } \\
\text { TRANSPARENCIA } \\
\text { INSTITUCIONAL }\end{array}$ & $\begin{array}{c}\text { SISTEMA } \\
\text { DE SALUD }\end{array}$ & $\begin{array}{l}\text { INSTANCIAS } \\
\text { SISTEMA } \\
\text { EDUCATIVO }\end{array}$ & $\begin{array}{l}\text { SERVICIO LEGAL } \\
\text { INTEGRAL } \\
\text { MUNICIPAL }\end{array}$ & $\begin{array}{c}\text { DEFENSORÍA } \\
\text { DE LA NIÑEZ Y } \\
\text { ADOLESCENCIA }\end{array}$ & $\begin{array}{l}\text { MINISTERIO } \\
\text { PÚBLICO }\end{array}$ & $\begin{array}{l}\text { POLICIA } \\
\text { BOLIVIANA }\end{array}$ & $\begin{array}{l}\text { ÓRGANO } \\
\text { JUDICIAL }\end{array}$ & $\begin{array}{l}\text { CASAS DE } \\
\text { ACOGIDA } \\
\text { Y REFUGIO } \\
\text { TEMPORAL }\end{array}$ & $\begin{array}{l}\text { GUARDERÍAS, } \\
\text { CENTROS } \\
\text { INFANTILES } \\
\text { INTEGRALESY } \\
\text { CENTROS DE } \\
\text { ACOGIMIENTO }\end{array}$ \\
\hline 產 & $\begin{array}{l}\text { PREVENCIÓN } \\
\text { ATENCIÓN Y } \\
\text { PROTECCIÓN } \\
\text { ACCIÓN PENAL }\end{array}$ & & 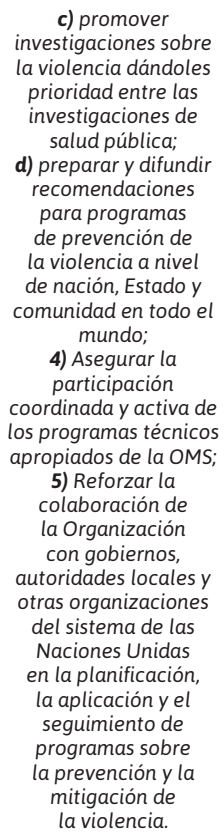 & & & 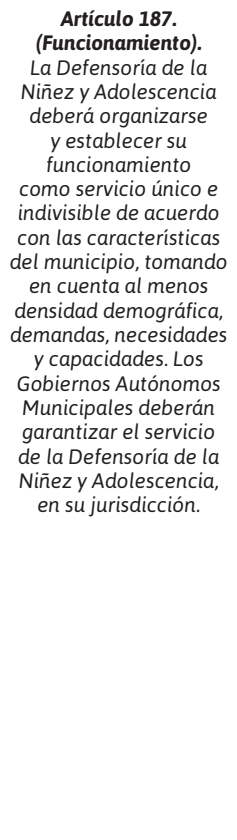 & & & & $\begin{array}{l}\text { 1. Acoger, proteger } \\
\text { y atender de forma } \\
\text { gratuita, a mujeres } \\
\text { en situación de } \\
\text { violencia, a sus hijas } \\
\text { e hijos y cualquier } \\
\text { familiar que se } \\
\text { encuentre } \\
\text { bajo su } \\
\text { dependencia } \\
\text { y esté en riesgo. }\end{array}$ & \\
\hline
\end{tabular}




\section{Propuesta Protocolo de intervención contra la violencia infantil}

De acuerdo a los elementos teórico-conceptuales, el marco contextual y el diagnóstico, se presenta como propuesta para el presente trabajo de investigación, la estructura del "Protocolo de intervención contra la violencia infantil".

El "Protocolo de intervención contra la violencia infantil" se encuentra divido en dos partes; la primera parte está conformado por la portada, la resolución Ministerial que aprueba el "protocolo de intervención contra la violencia infantil", índice; abreviaturas y siglas utilizadas; y presentación. Mientras que la segunda parte; desarrolla de manera detallada los contenidos esenciales del protocolo, la misma está dividida en seis capítulos que de manera general estarán comprendidos de la siguiente forma:

\section{Capítulo I. Marco teórico conceptual y contextual de la violencia contra niñas y niños, y el interés superior niña, niño y adolescente.}

En esta sección se abordarán, de manera detallada, los elementos conceptuales sobre cuestiones vinculadas a violencia contra niñas y niños, e interés superior de la niña, niño y adolescente, de ahí que se abordarán definiciones como ser violencia, violencia de género y generacional, violencia infantil, políticas públicas, situación de violencia, grupos vulnerables, prevención, atención, protección, acción penal, restitución y reparación de derechos fundamentales, entre otras.

Asimismo, en el marco contextual se considerá el tema de la violencia y su situación actual en el país, de manera general, así como el tema de la violencia contra niñas y niños; por otro lado, se estimará el amplio ordenamiento jurídico vigente sobre cuestiones de derechos humanos de niñas y niños, lucha contra la violencia y prevención de la violencia.

\section{Capítulo II. Etapas y componentes de la "Ruta de atención a niñas y niños en situación de violencia".}

El segundo capítulo está referido a la actuación frente a la violencia contra niñas y niños en el marco de su interés superior, conforme el "Protocolo de intervención contra la violencia infantil", que en su primera etapa comprende la "Prevención" que entre otros aspectos contempla la información, la formación y los mecanismos de actuación para afrontar los posibles brotes de violencia en determinados lugares, ello implica que se generen diferentes mecanismos de prevención, es decir una de las tareas fundamentales que tiene el Estado boliviano como la sociedad boliviana es la de erradicar la violencia en todas sus formas, en este sentido, las acciones deberán enmarcarse en procesos que deberán ser abordados desde la familia y el hogar, las unidades educativas, los centros de salud, las instituciones del Estado, 
las instituciones privadas, las cárceles, etc. La segunda etapa está referida a la "Atención y protección", que son dos acciones que van unidas y deben ser abordadas de manera conjunta, por lo tanto, la atención está referida a los servicios especializados que brindan las instituciones que coadyuvan en hechos de violencia y conocen de los mismos en sus diferentes dimensiones; asimismo, la protección está vinculada a los mecanismos que se utilizan desde las instituciones para abordar y coadyuvar en hechos de violencia. Ambas acciones están centradas respecto a hechos de violencia contra niñas y niños.

La tercera etapa "Acción penal", que contempla las fases de denuncia, investigación, persecución penal y control jurisdiccional a través de la justicia penal, respecto a la comisión o presunta comisión de delitos contra niñas y niños, previstos y sancionados por la normativa penal. La cuarta etapa "Reparación y restitución de derechos", donde se abordarán los aspectos de una indemnización económica, que muchas veces no resulta suficiente, asimismo se debe brindar el apoyo y la atención en los ámbitos jurídico, psicológico, social y de la salud, es decir brindar todo el apoyo en las diferentes instancias a niñas y niños víctimas de violencia. Por último, la reparación consiste en el hecho de que los mecanismos establecidos para la atención a niñas y niños debe implicar la garantía de que estos hechos no deben volver a repetirse en la sociedad, contra las víctimas que se atiende como con los demás niños y niñas, puesto que desde ya se constituyen en un grupo vulnerable.

\section{Capítulo III. Instituciones que operan el Protocolo de Intervención.}

El capítulo tercero abordará las argumentos referidos a las instituciones que le dan operatividad al "protocolo de intervención contra la violencia infantil", los cuales son: Ministerio de Justicia y Transparencia Institucional; Sistema de Salud; Sistema Educativo; Servicio Legal Integral Municipal; Defensoría de la Niñez y Adolescencia; Ministerio Público; Policía Boliviana; Órgano Judicial; Casas de acogida y refugio temporal; y, Guarderías, centros infantiles integrales y Centros de acogimiento.

\section{Capítulo IV. Funcionamiento del Protocolo de Intervención y articulación institucional}

Este capítulo desarrollará el proceso penal en lo concerniente a casos de violencia contra niñas y niños, lo cual contemplará el accionar de las diferentes instituciones que operan el "protocolo de intervención contra la violencia infantil", por lo que corresponde hacer énfasis en las previsiones normativas señaladas en los diferentes cuerpos legales que se encuentran plenamente vigentes en el país.

\section{Capítulo V. Aplicación del Protocolo de Intervención en las entidades territoriales autónomas (departamentales, municipales e indígena originario campesinas)}

La Constitución Política del Estado conforme la estructura y organización territorial del Estado ha previsto el nivel central como los niveles subnacionales (departamental, municipal e 
indígena originario campesino), al respecto se desarrollaron facultades (privativas, exclusivas, compartidas y concurrentes) así como, un catálogo competencial conforme las diferentes áreas de intervención, en este sentido, el Código Niña, Niño y Adolescente Ley 548 ha establecido una serie de competencias para el nivel central como los niveles subnacionales, se deben establecer los alcances de las competencias con las previsiones del presente protocolo.

\section{Capítulo VI. Seguimiento y monitoreo.}

Por último, esta sección contemplará la síntesis conforme a la actuación de las diferentes instituciones de referencia, así como el abordaje de sus atribuciones, lo cual deberá ser sistematizado en el "Sistema Plurinacional de Protección Integral de la Niña, Niño y Adolescente - SIPPROINA" que es el conjunto articulado de órganos, instancias, instituciones, organizaciones, entidades y servicios. Este Sistema ejecutará el Plan Plurinacional de la Niña, Niño y Adolescente, cuyos objetivos específicos, estrategias y programas, tienen como objetivo primordial, garantizar el pleno goce de los derechos de las niñas, niños y adolescentes

\section{CONCLUSIONES}

El ejercicio de los derechos fundamentales por parte de niñas y niños tiene como sustento el principio del interés superior de la niña, niño y adolescente. No obstante, dadas las actuales circunstancias y situación de vulnerabilidad de este grupo social, no están dadas las condiciones materiales y financieras para poder hablar de la plenitud y goce efectivo de los derechos fundamentales. Sin embargo, si bien la tarea es ardua y compleja, a través de la elaboración e implementación del "protocolo de intervención contra la violencia infantil", se podrá trazar la ruta a seguir, en el marco de la coordinación interinstitucional necesaria.

Para finalizar, la identificación y determinación de los elementos configurativos de la violencia contra niñas y niños, permitieron establecer un concepto nuevo, así como los alcances del principio del interés superior de la niña, niño y adolescente, sentar las bases y etapas de la ruta de atención a niñas y niños en situación de violencia, así como el planteamiento con los contenidos mínimos del "protocolo de intervención contra la violencia infantil".

\section{REFERENCIAS}

Conde, M. (2009). El acceso a la justicia de niños, niñas y jóvenes. Revista Instituto Interamericano de Derechos Humanos. Recuperado en https://www. corteidh.or.cr/ tablas/r25534.pdf

Corte Interamericana de Derechos Humanos Opinión Consultiva Oc-17/2002 de 28 de agosto de 2002, solicitada por la Comisión
Interamericana de Derechos Humanos Condición Jurídica y Derechos Humanos del Niño. Disponible en https://www.corteidh.or. cr/docs/opiniones/seriea_17_esp.pdf

De Bonis, M. (1998). Evolución histórico-social del fenómeno maltrato (Infantil) Implicancias Médico-Legales Actuales en nuestro país. Revista nuestro hospital. Año 2 N. ${ }^{\circ}$ 2. México 
Dworkin, R. (1989). Los derechos en serio. Ariel Derecho, Barcelona, 2a. edición

Fondos de Naciones Unidad para la Infancia, UNICEF (2006). Convenio sobre los derechos del niño. Unidos por la infancia 1946-2006. Madrid- España

Fondo de las Naciones Unidas para la Infancia, UNICEF. (2006). Hojas informativas sobre la protección de la infancia: la violencia contra los niños y niñas. Disponible en https:// www.unicef.org/spanish/protection/files/la violencia_contra.pdf

Gaceta Oficial de Bolivia. (2009). Constitución Política del Estado

Gaceta Oficial de Bolivia. (2014). Código niña, niño y adolescente Ley 548
Gutiérrez, I., y Acosta, A. (2012). La violencia contra niños y niñas: Un problema global de abordaje local, mediante la lap. Colombia

Ministerio de Salud y Protección Social, consultada el 24 de agosto de 2017. https://www. minsalud.gov.co/salud/ publica/ssr/Paginas/ Ruta-de-atencionintegral-para-victimas-deviolenciasde-genero.aspx.

Organización de los Estados Americanos (1969). Convención Americana sobre Derechos Humanos (Pacto de San José). San José, Costa Rica

Pulgar, J. (1996). Las raíces y las causas de la violencia. Tabanque: Revista Pedagógica, $\mathrm{N}$. 10-11. 62-70 